\title{
START TO END SIMULATION FOR THE SPARX PROJECT
}

\author{
R. Boni, M. Boscolo, M. Ferrario, V. Fusco, M. Migliorati, L. Palumbo, B. Spataro, C. Vaccarezza, \\ M. Vescovi, INFN-LNF, Frascati, Italy \\ L. Giannessi, M. Quattromini, C. Ronsivalle, ENEA Frascati, Italy \\ L. Serafini, INFN-MI, Milano, Italy
}

\section{Abstract}

The first phase of the SPARX project now funded by MIUR (Research Department of Italian Government) is an R\&D activity focused on developing techniques and critical components for future X-ray FEL facilities. The aim is the generation of electron beams with the ultrahigh peak brightness required to drive FEL experiments. A FEL source realization is foreseen within this program, which comprises two lines of activity: a) the use of the SPARC high brightness photoinjector to test RF compression techniques and the emittance degradation in magnetic compressors due to CSR, b) the production of radiation in the range of 3-5 $\mathrm{nm}$, both in SASE and SEEDED FEL configurations, in the so called SPARXINO test facility, based on the upgrade of existing Frascati $800 \mathrm{MeV}$ LINAC. In this paper we present and discuss the preliminary start to end simulations results for SPARXINO.

\section{INTRODUCTION}

SPARX is the project for a SASE-FEL X-ray source proposed by ENEA, INFN, CNR and Universitá Tor Vergata. The first phase has been funded by MIUR and by INFN: it is mainly focused on two lines. The use of the SPARC high brightness photoinjector [1] to develop experimental test on RF compression techniques and other beam physics issues, like emittance degradation in magnetic compressors due to CSR. Production of soft and hard X-rays in a SASE-FEL with harmonic generation, in the so called SPARXINO test facility, upgrading in energy and brightness the existing Frascati $800 \mathrm{MeV}$ Linac presently working as injector system for the DA $\Phi N E \Phi$-factory [2]. In the next sections we describe a preliminary layout of the SPARXINO test facility, the required $R \& D$ efforts and the start to end simulation results.

\section{THE SPARXINO TEST FACILITY}

A spectral range from $10 \mathrm{~nm}$ to $1 \mathrm{~nm}$ has been considered for the radiation. SASE-FEL's in this wavelength range require high brightness beam at the undulator entrance. In Table 1 a preliminary parameter list is reported for such a source, while in Fig. 1 the schematic layout is shown. It

Table 1: Electron beam parameters.

\begin{tabular}{|l|c|c|}
\hline Beam Energy & 1.2 & $\mathrm{GeV}$ \\
\hline Peak current & $1-2.5$ & $\mathrm{kA}$ \\
\hline Emittance (average) & 2 & $\mathrm{~mm}-\mathrm{mrad}$ \\
\hline Emittance (slice) & 1 & $\mathrm{~mm}-\mathrm{mrad}$ \\
\hline Energy spread (correlated) & 0.1 & $\%$ \\
\hline
\end{tabular}

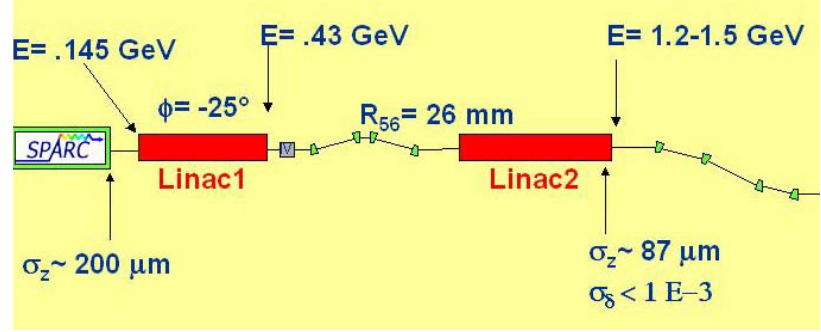

Figure 1: Schematic layout of the SPARXINO test facility.

consists of an advanced high brightness photoinjector followed by a first linac, Linac1, that drives the beam up to $430 \mathrm{MeV}$ with the correlated energy spread required to compress the beam in a subsequent magnetic chicane. The second linac, Linac2, drives the beam up to $1.2 \mathrm{GeV}$ while damping the correlated energy spread tacking profit of the effective contribution of the longitudinal wake fields provided by the S-band accelerating structures.

\section{The photoinjector}

This linac design integrates a rectilinear RF compressor in a high brightness photoinjector, as proposed in [3], thus producing a $300-500 \mathrm{~A}$ beam in the early stage of the acceleration. The SPARXINO linac will be the first SASE FEL experiment operating with RF and magnetic compressors in the same linac. According to the simulation results the beam compression at low energy $(<150 \mathrm{MeV})$, still in the space charge dominated regime, turns out to be feasible provided that a proper emittance compensation technique is adopted [4], a possibility that is not viable in a magnetic chicane. Moreover the propagation of a short bunch in the Linac1 reduces the potential emittance degradation caused by transverse wake fields, while a proper phasing of the linac can control the longitudinal wake fields.

The injector design for the SPARXINO test facility is based on the SPARC high brightness photoinjector [5]. It considers a $1.1 \mathrm{nC}$ bunch $10 \mathrm{ps}$ long (flat top) with 1.1 $\mathrm{mm}$ radius, generated inside a 1.6-cell S-band $\mathrm{RF}$ gun of the same type of the BNL-SLAC-UCLA one [6] operating at $120 \mathrm{MV} / \mathrm{m}$ peak field equipped with an emittance compensating solenoid. Three standard SLAC type 3-m TW structures each one embedded in a solenoid boost the beam up to $150 \mathrm{MeV}$. With a proper setting of the accelerating phase and solenoid field amplitude it is possible to increase the peak current preserving the beam transverse emittance. For the case presented here a setting has been chosen that provides a bunch average current of 450 A with a normalized $\mathrm{rms}$ emittance below 

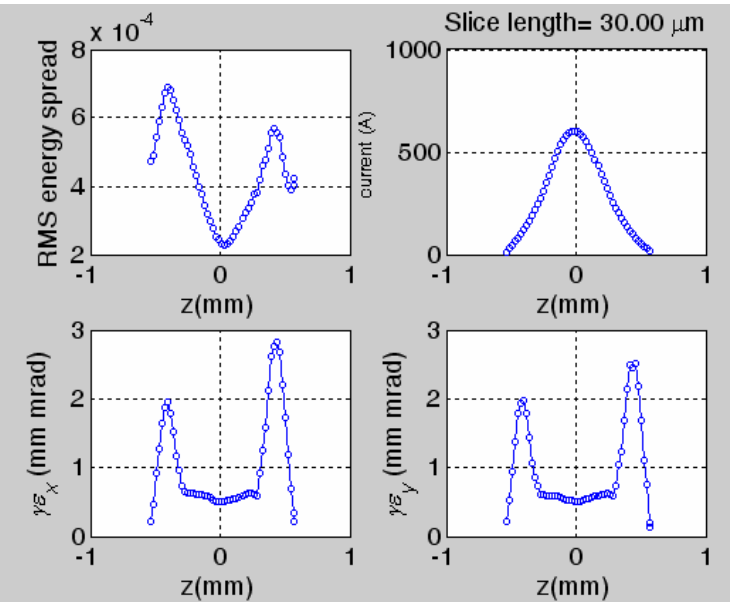

Figure 2: Energy spread, peak current and transverse emittance along the bunch, at the photoiniector exit.

$1 \mathrm{~mm}$-mrad [7]. The energy spread, peak current and transverse emittance along the bunch, at the photoinjector exit, are shown in Fig. 2, as obtained from Parmela simulation [8].

\section{The Linac}

The SPARXINO linac is based on the upgrade of the existing DAФNE injection facility. The DAФNE injection system is a $60 \mathrm{~m}$ long LINAC [9] equipped with $15 \mathrm{~S}$-band $(2.865 \mathrm{GHz})$ SLAC-type $3 \mathrm{~m}$ long accelerating structures driven by four $45 \mathrm{MW}$ klystrons each followed by a SLED peak power doubling system. At present it delivers $0.8 \mu \mathrm{s}$ RF pulses at a repetition rate of $50 \mathrm{~Hz}$ as required for the DA $\Phi$ NE operation. A quadrupole FODO focusing system is distributed along the entire linac. It accelerates the positron bunches emerging by the Positron Converter, up to the maximum energy of $550 \mathrm{MeV}$ and the electron bunches up to $800 \mathrm{MeV}$. A drift space about $15 \mathrm{~m}$ long is available at the linac output for the installation of the undulator. The Linac energy upgrade to 1.2 GeV can be achieved, as shown in Fig. 3, by upgrading the accelerating field of the existing units up to $25 \mathrm{MV} / \mathrm{m}$. The Linac waveguide network must also be modified in order to supply two accelerating units per RF station. This system configuration requires four new 45 MW klystrons. More over the availability for inserting four more SLAC-type sections will provide the possibility to reach a final energy of $1.5 \mathrm{GeV}$.

High beam brightness can be achieved by installing a

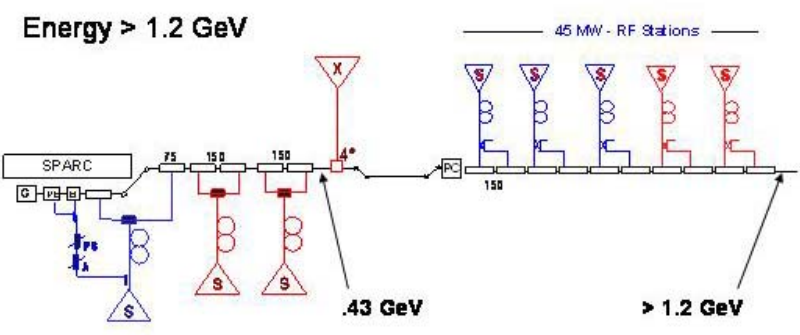

Figure 3: Scheme of the Frascati linac upgrading for SPARXINO and DA $\Phi$ NE operation.

copy of the $12 \mathrm{~m}$ long SPARC photoinjector upstream the DA $\Phi N E$ linac, with a minor modification of the existing building, and a magnetic compressor at $\mathrm{E} \approx 430 \mathrm{MeV}$ just at the entrance of the existing Positron Converter thus keeping the possibility to operate the linac as DA $\Phi$ NE injector. Nevertheless the full compatibility of the SPARXINO test facility with the DA $\Phi$ NE actual operation or future upgrade is one of the basic issues of our study.

\section{The lattice}

Moving from the necessity of using existing facilities the main task was the integration of both the photoinjector and the magnetic compressor sections in the DAФNE linac lattice, together with the design of a high energy dogleg able to drive the final electron beam to the undulator area while matching the existing building constraints. The proposed layout is schematically shown in Fig. 4; it provides the insertion of the photoinjector and the magnetic chicane before the existing Positron Converter (PC), while keeping untouched the positron source itself and the downstream 10 accelerating sections, (Linac2), and the existing quadrupole arrangement. The five accelerating sections that presently drive the DA $\Phi$ NE electron beam on the PC target, will moved to the interspace between the photoinjector exit and the magnetic chicane in order to provide the designed energy and chirp for the magnetic compression stage (Linac1). Finally the DAФNE thermoionic gun together with the prebuncher and buncher sections will be placed on a 15 degrees beam driving the electron beam to the entrance of the Linac1. At the end of Linac2 the SPARXINO beam first travels in the existing DA $\Phi N E$ transfer lines for about $34 \mathrm{~m}$, then is extracted and driven up to the undulator entrance via a

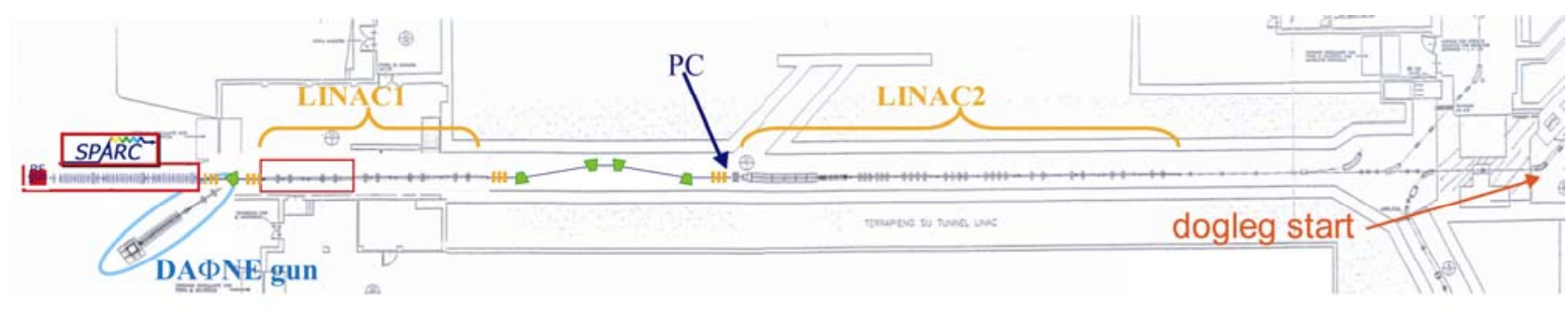

Figure 4: SPARXINO proposed layout. 


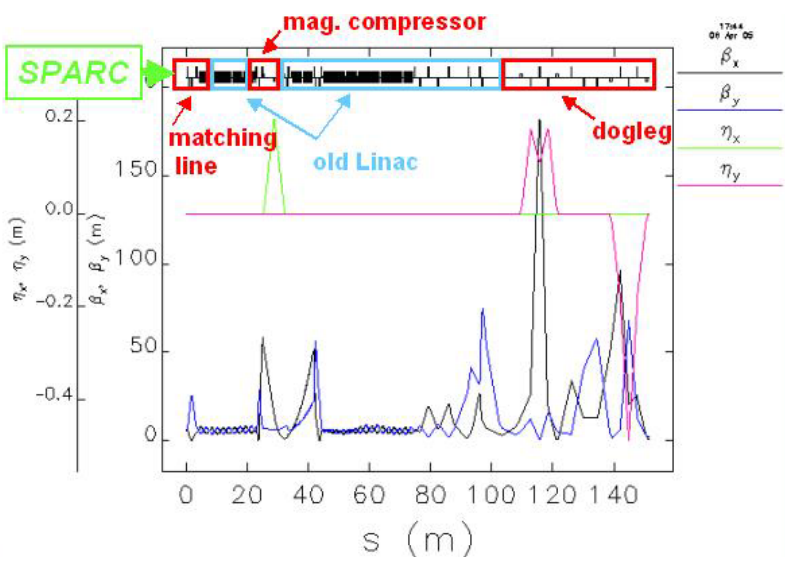

Fig. 5: Dispersion and betatron function for SPARXINO starting from the exit of the photoinjector up to the high-energy dogleg end.

four bend vertical dogleg that provides a total vertical offset of $\approx 3.4 \mathrm{~m}$ without affecting the final beam quality. This is meant to leave a total access to the DAФNE experimental area at the road level, while driving the electron beam at the foreseen underground undulator and experimental area. In Fig. 5 the optic functions are reported starting from the photoinjector exit up to the end of the high-energy dogleg.

\section{SIMULATION RESULTS}

On the basis of the described layout the photoinjector out coming beam, $\left(<\mathrm{I}_{\text {peak }}>\approx 450 \mathrm{~A}\right.$, slice analysis in Fig. 2$)$, has been tracked using Elegant code [10] with 50k particles. The results are reported in Fig. $6-7$. The final beam has a peak current $\mathrm{I}_{\text {peak }} \approx 1.2 \mathrm{kA}$, a rms length of $\approx$ $87 \mu \mathrm{m}$, and a transverse normalized emittance $\varepsilon_{\mathrm{x}, \mathrm{y}}<1 \mu \mathrm{m}$ on both planes along most of the bunch length. Applying Ming-Xie's formulas [11] for the case of $\lambda=5 \mathrm{~nm}$ a saturation efficiency is reached of $\approx 85 \%$ for a $22 \mathrm{~m}$ saturation length, undulator $\mathrm{k}=1.54$ and undulator period of $2.80 \mathrm{~cm}$, with a saturation power of $\mathrm{P}_{\max } \approx 3 \mathrm{GW}$.

\section{CONCLUSIONS}

The SPARX R\&D project has been approved by the Italian Government and funded in June 2004 with a three years schedule. The critical components for an X-ray FEL source, such as the RF-compression scheme, magnetic chicane, etc. will be tested during the phase II of the SPARC project and assembled in a high energy and high brightness linac, the SPARXINO test facility, by upgrading the existing Frascati linac. A first general layout for SPARXINO has been proposed taking into account the compatibility with the actual DAФNE operation and its future upgrade, together with the existing building constraints. Start to end simulations have been presented using an innovative scheme of bunch compression which comprises a mixed RF and magnetic compression technique.
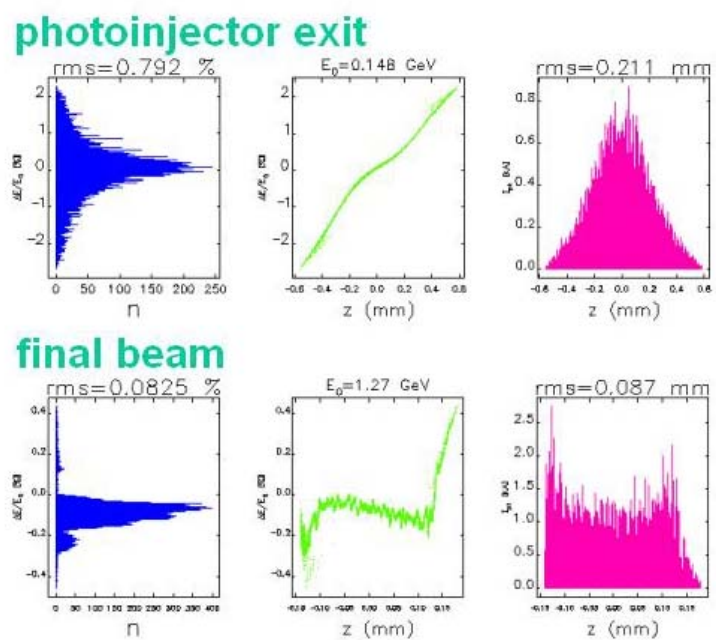

Figure 6: Energy (left) and axial (right) e distributions and longitudinal phase space (center) at the photoinjector exit (up) and at the high-energy dogleg end (bottom).

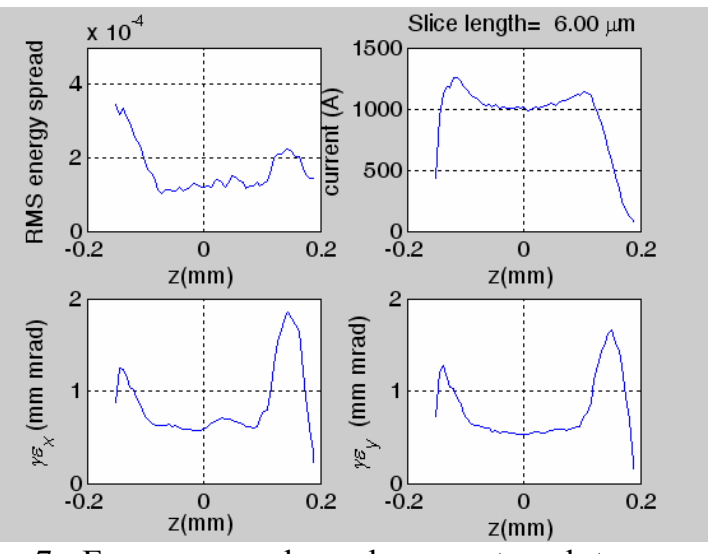

Figure 7: Energy spread, peak current and transverse emittance along the bunch, for the final beam.

\section{REFERENCES}

[1] SPARC Project Team, Sparc Injector TDR www.lnf.infn.it/acceleratori/sparc/.

[2] G. Vignola et al., "DA $\Phi N E$, The Frascati Phifactory", Proc. of PAC 1993, Washington

[3] L. Serafini and M. Ferrario, Velocity Bunching in PhotoInjectors, AIP CP 581, 2001, pag. 87

[4] M. Boscolo et al., Beam Dynamics Study of RF Bunch Compressors for High Brightness Beam Injectors, Proc. of EPAC 2002, Paris.

[5] L. Serafini, RPPT013, this conference

[6] D.T. Palmer, The next generation photoinjector, $\mathrm{PhD}$. Thesis, Stanford University

[7] C. Ronsivalle et al., WPAP009, this conference.

[8] J. Billen, "PARMELA", LA-|UR-96-1835, 1996

[9] S. Kulinski et al., DAФNE Tech. Note LC-4

[10]M. Borland, "elegant: A Flexible SDDS-Compliant Code for Accelerator Simulation,"Advanced Photon Source LS-287, September 2000.

[11]M. Xie, "Design optimization for an X-ray Free Laser driven by SLAC linac", Proc. of PAC 1995, Dallas 